\title{
Funeral Practices in Ghana and the United States: A Cultural Comparison
}

\author{
Alice Boateng, Ph.D., MSW ${ }^{1} \&$ Linda Anngela-Cole, Ph.D., LCSW ${ }^{2}$ \\ ${ }^{1}$ Department of Social Work, University of Ghana, Legon, Ghana. \\ ${ }^{2}$ School of Social Work, University of Nevada, Reno. \\ Correspondence: Linda Anngela-Cole, Ph.D., LCSW, Associate Professor - School of Social Work, Mailstop 090, \\ University of Nevada, Reno, NV 89557, Lanngela@unr.edu
}

Received: October 22, 2015

Accepted: November 9, $2015 \quad$ Available online: November 27, 2015

doi:10.11114/ijsss.v4i1.1221

URL: http://dx.doi.org/10.11114/ijsss.v4i1.1221

\begin{abstract}
Across the life course, culture is never more evident than at the end of life. Due to the great variability of end-of-life practices and observed customs across the world, it is important to understand cultural differences from a variety of perspectives. This study provides a comparative analysis of death and funeral practices in three cultures: (1) Akan culture in Ghana, West Africa; (2) African-Americans born in the U.S.; and (3) European Americans in the United States. Two frameworks are used: (1) the biopsychosocial, spiritual, cultural framework; and (2) a framework of independent/interdependent cultural values, to compare the three cultural groups in a qualitative exploratory study with 20 participants from each group. The purpose is to explore whether African-American end-of-life traditions are more similar to the majority culture's (European American) customs in the United States or to customs still practiced in Ghana today. This study also considers how the findings might be used to enhance culturally sensitive services in the provision of end-of-life care. Findings suggest that, although African-Americans have lived in the United States for over a century, their culture retains aspects reflective of African culture and traditions related to end-of-life activities. This study offers unique findings that address issues of cultural humility, sensitivity, and competency. An understanding of these issues is crucial for anyone working in human services and for practitioners supporting dying and bereaved families.
\end{abstract}

Keywords: death, funerals, culture, biopsychosocial, Akan, Ghana, European-American, African-American

\section{Introduction}

Every culture has its own worldview with beliefs about the meaning and purpose of life and what happens after death. These beliefs determine how people interact with death. For example, people that believe in life after death may find the loss of a loved one more bearable, due to a belief that they may see their loved one again. Due to the great variability of end-of-life practices and observed customs across the world, it is crucial to understand cultural differences from various perspectives. For the current study, we have chosen a non-Eurocentric perspective as a means of understanding end-of-life cultural practices among three groups: (1) Akans in Ghana, West Africa; (2) European Americans in the United States; and (3) African-Americans born in the United States. This analysis is intended to serve as a beginning dialogue regarding some notable similarities and differences among these three historically intertwined cultural groups:

We selected these groups due to the observable cultural differences identified when working professionally with all three groups at the end-of-life. We initially compared death practices in Ghana with practices commonly found in the United States. European Americans are the predominant cultural group in the United States, representing non-uniformity and heterogeneous values in end-of-life practices. Death practices in the U.S. seemed worthy of a comparative analysis with those found in Ghana, a culture that still practices traditional and homogeneous ways at the end-of-life. Because African Americans have historical origins in West Africa, we included their death practices in the analysis. We used a Ghana-centric perspective in comparing these groups. Such a perspective is rarely seen in the literature. In this study, a Ghana-centric approach involves a primary focus on death and funeral customs in the Akan culture from Ghana. This perspective reflects a desire to compare traditional cultural practices (e.g. the Akans), with cultural practices that are found in the United States where a multitude of customs are practiced.

\section{Importance of Exploring Cultural Death Practices}

As we explored end-of-life and cultural issues in professional practice and in the literature, we were amazed by the 
ways in which human beings retain, adapt, or give up their native practices and customs. We believe that it is important to understand why some groups retain their traditions while others adapt or abandon them. Therefore, we focus this study through a cultural lens comparing bio psychosocial, spiritual, cultural and economic factors that influence funeral practices in each of the three cultures. Additionally, we examine the similarities that African-American funeral practices and end-of-life traditions have in common with the practices of European Americans, in the United States, and with the practice of Akans in Ghana, West Africa today. This is important when considering the provision of end-of-life services in today's multicultural communities. An understanding of how culture is expressed at the time of loss is imperative if services are to be offered with cultural sensitivity or, even better, from a place of cultural humility. This study offers an exploratory perspective for the beginning of a research agenda that aims at understanding more deeply the ways in which cultural traditions have changed or maintained, and have shaped death and funerals among the cultural groups in this study.

\section{Theoretical Perspectives Applied}

Two theoretical perspectives are used in our analysis of funeral practices. The first is the biopsychosocial framework commonly used in social work and medical literature (Borrell-Carrió, Suchman, \& Epstein, 2004; Engel, 1977). We have added the perspectives of spiritual, cultural, and economic factors to the framework, as these are commonly assessed in professional practice settings, and cannot be ignored when considering end-of-life issues. The second framework used in this analysis is the independent / interdependent framework often used when comparing cultural groups internationally (Hofstede, 1980; Markus and Kitayama, 1991). This perspective is uniquely important in international cultural comparisons, as it helps frame a multitude of cultural actions into understandable terms. For example, for people coming from an independent cultural group or frame of familial reference, each family member is encouraged to choose their actions, such as their role in caregiving for older or infirmed members; whereas those coming from an interdependent familial cultural group would be more likely to act in accordance with social norms of that group, such as providing care without questioning one's role in caring for older or ill members. A combination of these frameworks serves as a basis for explaining the cultural similarities and differences found in this exploration of the three groups' death practices.

\subsection{Bio-psycho-social framework.}

This model posits that three types of factors-biological factors, psychological factors, and social factors-play important roles in human functioning within the context of disease and illness (Borrell-Carrió, Suchman, \& Epstein, 2004; Engel, 1977). The model has been used as a guiding framework for theoretical and empirical exploration over the past 30 years (Armitage \& Conner, 2000). It is used here as a means for comparing the cultural groups identified in this study. Although the original framework suggests interconnectedness among the biological, psychological, and social functions of all human conditions, each aspect of the model may be unique in its own right when used for comparative purposes. For example, with regard to disposition of the body after death (representing the loss of the physical body), some individuals believe that cremation of the remains is appropriate, whereas others believe that cremation involves decimation of the body, and that only embalming and burial are appropriate. In this study, the authors seek examples of cultural trends in death practices and beliefs. All three aspects of the model are compared in this analysis (biological, psychological, and social factors). In addition, the authors have included two other dimensions, that of the spiritual and cultural components that influence end-of-life practices. Economic factors are also considered as part of the cultural context. These additions reflect the mind-body-environmental connections that have received greater attention in recent years. (Laurie and Neimer, 2008; Smith, 2002).

\subsection{Theory of Independent and Interdependent Construal.}

This theory suggests that many people raised in non-Western cultures possess interdependent self-construals, which portray the person not as separate from the social context but as more connected and less differentiated from others in their culture. As such, people in these cultures link with others to fulfill obligations, and they partake in many interpersonal relationships. In these cultures, the essential features of the self are its interdependent and public parts (Markus and Kitayama, 1991). This concept is commonly found in Japan, China, Korea, South America, and Africa.

Many people from Western cultures, however, possess independent self-construals that feature the person as an individual. Thus, Western cultures (such as those in North America and Europe) tend to be individualistic in nature. This perspective emphasizes the needs of the individual over the needs of the group as a whole, where individual members are seen as autonomous, independent, and self-reliant. Contrasting the Western concept of the independent self with the non-Western concept of interdependence, this perspective suggests that the non-Western concept presumes an obligation to others and that the individual is seen as a social being who engages in certain roles with specific people. Self-sacrifice, reciprocity, willingness to help others, dependability, and other characteristics are of greater importance to the interdependent culture. In contrast, from the independent perspective, social behavior tends to be dictated by the 
preferences and attitudes of individuals. People see each other as only loosely connected and value personal goals above the goals of the group. Simply put, independent cultures reflect values that the first individual's loyalty lies with himself or herself, whereas in an interdependent culture, the individual's loyalty lies with the culture or group.

The distinction between independent and interdependent cultural values is an important one in an examination of behaviors and motivations related to end-of-life traditions. As suggested above, these differences provide a framework for comparing an intact (homogeneous) culture, such as the Akan culture of Ghana, with the heterogeneous European American traditions that have developed in the United States. What is not so clear, but of great interest, are how cultural traditions of a historically interdependent culture (Africans) exposed to a predominantly independent majority culture in the United States for hundreds of years, are impacted by the majority culture's practices. It is unclear how exposure to a majority independent culture has influenced African-American end-of-life beliefs and practices. This analysis is intended to provide a context for comparing and understanding the variety of end-of-life traditions in the three cultural groups (the Akan of Ghana, European Americans, and African-Americans).

\subsection{Approach to the Analysis}

This analysis begins with the application of the biopsychosocial-spiritual-cultural framework to death traditions in Akan, Ghana. In applying the model to this a group, we observe clear cultural patterns that would likely be reported in a similar way by anyone belonging to the Akan tribe. We then use the same biopsychosocial-spiritual-cultural perspective to describe two cultural groups in the United States (Americans of African descent, and those of European descent). We overlay this analysis with a lens reflecting the independent/interdependent cultural values observed in the three cultural groups. We conclude with a discussion of the implications of the differences and similarities found among the three cultural groups in this study, and further explore how these findings might be used in the provision of end-of-life care and professional services.

\section{The Akan Understanding of Death}

In the Akan society, there is an intimate link between life and death. The Akans believe that when a person dies, his or her soul ( $k r a)$ becomes a spirit (saman) and this spirit assumes supernatural powers (Rutledge, 2001; Tufour and Donkor, 1997). To the Akans, the ancestral spirits are real and omnipresent, watching over every aspect of the daily lives of living descendants (Kwakye-Nuako, 2011). The Akans believe that the ancestors (the dead) hover around them and protect them. This implies a relationship between the dead and their living descendants. In Akan society, this belief is connected to an individual's value: The further a living descendant is from these beliefs, the more unrealistic and valueless he or she is seen to be in Akan society (Ephirim-Donkor, 1997). As Ephirim-Donkor rightly put it, some Akan people refer to the ancestors as gods, because they acknowledge the strength of their ancestors' vital force, but never as God, for they also acknowledge the overall power of the supreme God.

\subsection{Biopsychosocial Aspects: End-of-Life Practices as a Life Celebration or Social Event (Akans)}

In Akan society, the death of an individual can be characterized as a "good death" or a "bad death" (Geest, 2004, p. 899). The concept of good death characterizes the passing on someone who lived to old age and was successful in life. For example, the deceased may have had descendants, worked hard to support their well-being, and provided for their education. The individual was well respected by family and in the community (Geest, 2004, p. 899). When such a successful person dies in old age, the death is celebrated. Wailing, sorrow, grief are minimized. The bereaved family and people close to the deceased may wear clothes made of white fabric on the burial day (which is always on a Saturday); the clothing signifies victory. The Akans hope for good death. Conversely, Akans believe that younger people cut off by accident or unexpected illness did not achieve all that they would have. Thus, untimely death is seen as bad death. In funerals for those who faced a bad death, there is much wailing, tension, anger, and even bitterness. Mourners wear clothes made of black and red fabric, signifying great sorrow.

Akan funeral events are celebrated in the matrilineal hometown of the deceased), and every Akan is a citizen of his or her matrilineal hometown (Witte, 2001). This is because the Akans practice matrilineal inheritance. The hope of most Akans to accomplish something in life, to die in old age, and to be buried in his or her hometown, where his or her ancestors were laid to rest (Arhin, 1994). Many Akans live outside of Ghana. Even in the midst of widespread migration, hometown solidarity and identity are strong bonds for the Akans (De Witte, 2001). Akan society is communalistic and based on the concept of social capital; that is, relationships are characterized by norms of trust and reciprocity (Fukuyama, 2001; Putman, 2000). The underlying assumption is that Akans have certain obligations toward each other (Arhin, 1994). These include the obligation to provide social support in cash and in kind to people in times of need. For instance, people at home in Ghana can call on members living abroad to send money to help during times of sickness and death as well as for happy occasions such as marriage ceremonies. Social capital makes possible the continuing existence of the clan, tribe, and community as a whole. Funerals express a sense of commonality that involves communities, towns, villages, and even relatives living abroad (Arhin, 1994; Witte, 2003). 


\subsection{Cultural Aspects: Death and Tradition (Akans)}

The Akan funeral ritual is a long process that starts on the day of death and continues through the 40th day, when the deceased is laid in state for viewing. A celebration is held 1 year after the individual's passing, and some families hold yearly celebrations (Witte, 2001; Geest, 2006). The whole funeral is interactive. It is a reunion: All living relatives, friends, and community members come together to share their grief and solidarity in a single ritual. People meet old friends and make new ones. Family conflicts are settled. Social networks and ties are forged. All of these relationships aim to ensure society's strength through generations. Music and dance form an integral part of Akan funeral ritual. In the olden days, it was mainly traditional music and dance. However, the Akan culture and civilization have been altered by the European colonization of Ghana. Today, Akan funeral rituals consist of music and dance from traditional Akan culture, as well as from the Western world. Perhaps, this kind of compromise is intended to satisfy the different generations present at the funeral. Additionally, a poetic orator is typically present to pay tribute to the deceased. Funeral attire is part of the culture. As we stated previously, mourners wear red and black clothing to express great sorrow or to signify that the death was an untimely one. Mourners wear white clothing to signify a good death and a celebration.

\subsection{Spiritual Aspects: Death and the Transition to Ancestorship (Akans)}

Prayers to God and to the ancestors are major components of Akan death traditions and of the funeral rituals. In fact, such prayers are common in all Akan rituals. For instance, the Akans pray to God and the ancestors during the funeral preparations, requesting a successful funeral, because they believe that the ancestors have obligations towards the living generation. The final phase of the Akan journey to the ancestors is spiritual and so special that spiritual preparations are made. For instance, libation is poured to inform the ancestors of the newcomer's approach. In addition, various gifts and special possessions accompany the deceased in his or her coffin and into the ancestral kingdom. "Greet all who have preceded us, and tell them we are well"; "Repay all who caused you harm, and are responsible for your death"; "Go and prepare a place for us," and other wailing messages are sent to the ancestors through the spiritual personality of the dead person. In this way, the mourners reinforce the belief in the ancestors and ancestral power (Ephirim-Donkor, 1997, p. 133). The Akan people believe that they are accountable to their ancestors, that they should behave well, and that they should not do any evil thing because it may incur ancestral wrath. They also believe that, as living descendants, they represent and should project the good image of the ancestors, the clan, and the tribe. The Akans see their ancestors as sages, judges, and mediators. Having lived on this earth, ancestors died and resurrected. Having been vindicated, the ancestors have achieved a state of immortal existence comparable to that of God, though not God, because the ancestors cannot change God's created order (Arhin, 1994; Ephirim-Donkor, 1997).

\section{Death in the United States: European American Influenced Traditions}

Making comparative statements about death practices in a country as diverse as the United States is nearly an impossible task. However, some commonalities may be noted and studied from literature. For this analysis, we identify some common practices of European Americans that could be observed in many communities within the United States. In the following section, we also take this approach in analyzing funeral practices that can be widely observed in many predominantly African-American communities. This analysis speaks to general observances but does not address individual differences, of which there are many in a country as diverse and heterogeneous as the United States. To substantiate examples, we reference specific communities, religious groups, and geographical areas, but we do not imply that the examples represent all European Americans or all African-Americans.

\subsection{Biopsychosocial Aspects: Funeral as a Life Celebration or Social Event (European Americans)}

Two interrelated concepts predominate European American understandings of the biological aspects of physical death. First, European American attitudes about death lack the concept of a good death. Second, the European American puritanical history is one of denying death. Thus, death is always viewed as a negative event. The death of a young person is seen as a tragedy - the end of a life unlived - and the death of an older person is seen as a failure of efforts to sustain life via technology and medicine. This is a unique cultural perspective. As we have noted, other cultures consider the death of an older person or of one who is suffering to be quite a good death. In U.S. medical culture, there is a tendency to take the perspective that life should be preserved at all costs (Aries, 1974; Laderman, 2003).

This tendency is evidenced by technological advances for life support measures and policies surrounding the use of these technologies. Additional evidence may be found in other health care policies such as advance directives. Callahan (2009) notes that, as medical research and technology have advanced, death has become less of a natural occurrence and more of a manipulated event. With regard to psychosocial aspects of death, researchers have found that European Americans have fewer outward expressions of grief, emotional and physical, than have other culture groups (Oltjenbruns, 1998). The setting and mood for European American funerals are generally somber, with slow organ music and a steady tone of speaking. These features deter attendees from more emotional expressions of grief as such 
expressions are seen as incompatible with the surroundings (McIlwain, 2002). In terms of emotional expressions at funerals, the difference between European Americans and African Americans is not the ability to express emotions but rather the freedom in the range of expressions. There is an expectation that the emotional level of the attendees will match the mood of the service, and wailing is considered to be inappropriate in a solemn setting. McIlwain (2002) finds that European Americans generally shed tears and cry at the services but refrain from boisterous outbursts. Should such outbursts occur and disrupt the service, funeral directors usually respond by escorting the grieving person away. Grieving is seen more as an individual reaction, to be done in private, than as a community behavior.

Giblin and Hug (2006) describe funerals as countercultural phenomena because funerals give a sense of finality to the death of the loved one in a culture that denies death and avoids the subject. In such a culture, the funeral is the one forum for confronting that denial and addressing the loss. A funeral is neither a time for celebration nor a time for socialization (McIlwain, 2002). It is also not a time to connect to the deceased but a time for transitioning to fill the void left by the deceased in the family system. Family members adjust to new roles, and tension often runs high. This can lead to the intensification of family conflicts. Although some European Americans embrace the notion that death can be celebrated, it is often an individual or family value that determines whether one's death is expressed in a somber, quiet fashion, or in an open celebration of the deceased's accomplishments in life.

\subsection{Cultural Aspects: Death and Tradition (European Americans)}

Historically, death customs in the United States have varied by religious affiliation. Yet, in the context of specific religions, traditions were and continue to be held in great regard. For example, traditions followed in Catholic funerals might include cremation but burial is still expected and most often the case. Wakes are held the night before the funeral, and it is normative for mourners to view the body during the wake. In some Lutheran and other Christian (non-Catholic) denominations, individual preferences are more likely to be explored, tolerated, and sometimes celebrated. For example, if a parishioner (or the family) prefers cremation over burial, the service could still be held in today's church environment. Among U.S. citizens of European descent, individual preferences tend to outweigh pressures placed on society by traditions. As described above, the opposite is typically true in Akan culture: Everyone agrees on the traditions, they are rarely questioned, and all participate. In the United States, the preference of the individual—for burial, cremation, or some other disposition - is considered, honored, and carried out to the best of the family's ability (Giblin and Hug, 2006). In fact, some may choose to have their remains shot out of a cannon, or frozen through cryogenics, or shipped into space (Pappas, 2011). These options are not always possible, but individuals expressing such preferences would be considered eccentric, not ostracized by the community. The possibility of honoring the preference would likely be explored, particularly if money for doing so were available. Another tradition that may or may not be observed by European Americans is the practice of marking the anniversary of a death. There are no specific ceremonies, except for traditions perhaps held by individual families. For example, if an individual liked a certain type of liquor and always had that liquor on his or her birthday, the family might gather at the grave site on the deceased's birthday, share that liquor, and perhaps pour some on the grave. Such practices are typical among adherents to a certain religion or people from a particular ethnic heritage. Some families do not miss this occasion and may have paid this homage to the deceased for years (Laderman, 2003). The point is that the tendency toward individuation in U.S. traditions for the living follows into traditions concerning death. The disposition of remains and the nature of celebrations or mourning are determined by the individual, his or her family, and financial considerations (Giblin and Hug, 2006; McIlwain, 2002).

\subsection{Spiritual Aspects: Death and the Transition to Ancestorship (European Americans)}

Spirituality in the United States is not yet cohesively defined. Some define it in a religious context; others use a more universal or other-worldly definition. This is in great contrast to the understanding of spirituality in other societies. For example, we have seen that, in the Akan culture of Ghana, spirituality at death is typically expressed as ancestor worship. In European American culture, ancestor worship is definitely not the norm. According to the $2^{\text {nd }}$ author of the present study (European American) it is often the case that European Americans report "speaking to" the deceased, especially to lost spouses, but they rarely believe that the deceased "really hears them." She states further that "as much as they might hope that they are heard or that the deceased is speaking to them (or sending them signs), most European Americans would be reticent to admit that these feelings are anything other than an expression of hope (e.g., hope that they are heard by the deceased). Admission that these feelings are more than hope raises the fear that others will think them mentally ill."

\section{African-American Concepts of Death}

\subsection{Biopsychosocial Aspects: Funeral as a Life Celebration or Social Event (African-Americans)}

Many African-Americans tend to have strong ties to rituals associated with funerals and the end of life. According to Jamieson (1995), being responsible for their own dead, was one of the African cultural practices that slave masters 
allowed African Americans during slavery. Thus, slaves would gather at plantations for the funerals of family members, and this was the only time that slaves were permitted to meet in groups (Jamieson, 1995).

Today, African Americans celebrate the death of older adults and view younger death as bad death, an event filled with grief and deep sorrow. They see the funeral of an older adult as a celebration of the deceased's life on earth. They mark this event with music and dance (Barrett, 1995: Jamieson, 1995). It is noted from the literature that funerals form a crucial part of the African American experience. For instance, the importance of family gathering for funerals, the preoccupation with preparation of meals, the practice of traveling distances to attend funerals, and the tradition of wake keeping have their roots in African culture (Barrett \& Heller, 2002). African-American culture sees the funeral event as a time to work out interpersonal conflicts in the family. Family members are obliged to attend and to contribute to the funeral expenses. In general, African-American culture is collectivist and places a strong value on community. In view of this, the practice of gathering with family at the time of a member's death is obligatory. It is hypothesized by Laurie and Niemer that bereaved African-Americans will be less likely to seek professional help and more likely to seek informal support from their own community, than other groups, such as European Americans (Laurie and Niemer, 2008). Several authors mention the accepting attitude that many African-Americans have toward death; they view it as a natural part of life and as a transition into the next life (Barrett \& Heller, 2002; Clements et al., 2003; Smith, 2002). As we have noted, African- Americans recognize the concept of a good death in the passing of someone at an advanced age or someone whose death is a release from struggle. They also recognize the concept of a bad death, which characterizes the unexpected passing of a younger person or a violent death. This perception likely dates back to the era of slavery. Noting that African-Americans come from a history of sudden death and loss, Barrett (1995) states that funeral practices, such as the jazz funeral, have been essential in the grieving process. Whether the death is considered good or bad, a celebration is usually held in honor of the deceased's life to help him or her cross over into the next life (Coclanis and Coclanis, 2005; Moore, 2003).

\subsection{Cultural Aspects: Death and Tradition (African-Americans)}

Physical attendance at the funeral of a family member or friend is of great importance to many African-Americans, and it is obligatory (Perry, 1993). Reluctance to attend a funeral may be met with admonishments and criticism by other family members. Attendance is a way to pay proper and final respects to the deceased and to the deceased's family. Often, the funeral will be delayed for several days or a week to give attendees time for travel (Clements et al., 2003). This is done so that the family members can say goodbye to the deceased in person for the final time. In a study conducted by Lobar et al. (2006), African American participants reported the strong belief that burial should not occur until all of the family or a special priest is present. In African American culture, burying a loved one in a befitting style is of great importance. A funeral is not simply for the immediate family but also for community members with ties to the deceased. It is a celebration and appreciation of the deceased's contributions to others. Upbeat music and singing are parts of the traditional African American funeral practices (McIlwain, 2002). Personalized tributes are common: reading from poems and playing the deceased's favorite song are ways to comfort the family and demonstrate that the deceased lived a full life. In addition, members of the community fulfill cultural roles. Perry (1993) notes church nurses who help out during the funeral and flower girls who escort the casket. Both of these roles are performed with the thought of assisting and comforting the family of the deceased. These roles are unique to the African American culture.

\subsection{Spiritual Aspects: Death and the Transition to Ancestorship (African-Americans)}

African-Americans rely on faith, hope, prayers, and people to cope with death. A study by Taylor, Chatters, and Jackson (2007) report high levels of spirituality, religious participation, and religious coping among African-Americans, who believe that death is not a person's final end but a transition to the other world, either to heaven or to the ancestral world. Noting that African Americans experience a spiritual connection with the deceased, the study indicates that their spirituality represents a merging of African and Christian traditions. However, as Barrett and Heller (2002) observe, African-Americans who are traditional and Afrocentric are more likely to have a profoundly spiritual approach to commemorating the passing of others to dying, than those who are nontraditional. Generally, belief in life after death is a common and fundamental concept in the African American experience. In Barrett and Heller's study (2002), many African Americans reported the belief that the dead remain close to the living, assist in times of need, and share their joys. To this community, death may be stressful but the belief that the dead are spiritually present is a consolation. The strong sense of family is prevalent in the African-American community, and individuals are considered family members even after they have passed away.

\section{Methodology Used in This Study}

\subsection{Research Design \& Research Questions}

This comparative study employs an exploratory qualitative methodology. This approach was chosen to ensure that data are rich in detail and thus provide insight into the participants' lived realities (Patton, 1990). Participants answered 
survey questions posted on the Survey Monkey website (http://www.surveymponkey.com). Data were analyzed for thematic content by the investigators, and contextually verified by cultural representatives from each group. Themes were extracted for comparisons of the three cultural groups. The study sought to address the following research questions:

1. How do the biopsychosocial factors in each of the three cultures influence funeral practices?

2. How do spiritual and cultural factors influence funeral practices?

3. Are African-American death rituals and end-of-life traditions more similar to the customs of the majority culture (European American) in the United States or to the customs still practiced in Ghana and Africa today?

4. How can information from this comparative study be used in the provision of end-of-life care to enhance culturally sensitive services?

\subsection{Sample Selection}

Individuals qualified to participate in this study were adults over the age of 18 and from one of the three ethnocultural groups: (1) Ghanaian (Akan); (2) European American; and (3) African-American (born in the U.S.). All participants were able to read and understand English, access the Internet, and complete the survey on the Survey Monkey website. Sixty participants were selected - 20 from each cultural group. Qualified participants were identified with a snowball sampling method.

\subsection{Data Collection}

Participants were recruited through several means: Within one month after obtaining approval from the Institutional Review Board, recruitment letters were emailed or sent to the populations of interest (European Americans, AfricanAmericans, and Ghanaian Akans in Ghana and the United States). Flyers were posted at churches and in the offices of organizations where these groups meet in the metropolitan area around Reno and Sparks, NV. Flyers were posted to professional organizations such as the National Association of Social Workers and the National Association of Black Social Workers. Follow-up emails were sent to some of the potential participants through list serves, two weeks after the initial flyer distribution to address questions and provide them with details regarding how to access the study's survey. Potential participants contacted the researchers via email. If they were eligible to participate, the researchers sent them an email message with directions on how to access the survey through the Survey Monkey site. Upon accessing the survey, they were shown a consent form and agreed to participate before they were shown questions presented in an open-ended (qualitative) format. The survey remained accessible until a sample of 20 was obtained from each group. All participants answered questions in six categories. This phase took approximately 20 minutes. There was an opportunity for participants to enter a raffle drawing for a \$50 gift card from Starbucks. For the drawing, participants were required to complete all survey questions and give contact information. The $\$ 50$ gift card was purchased by the investigators. At the end of the survey period the names of all participants who stated a desire to be in the raffle were placed in a hat and one name was drawn by an independent person (not the investigators). Participation in the drawing was optional, and participants were not required to give contact information if they did not want to be eligible for the drawing.

\subsection{Ethical Considerations}

The email invitation clearly stated that participation was voluntary, and the information sheet reinforced this point. Participants were free to opt out any time, even after beginning the survey. This was stated on the consent form completed before participants accessed the survey. The consent information was in clear English and did not use jargon. The researchers clarified and explained any features that potential participants inquired about. Participants could contact the researchers for further clarification at any time. English is the second language of some of the participants (the Akans of Ghana), and the Ghanaian investigator was available to provide clarification if the need arose.

\subsection{Data Analysis}

The data were downloaded from Survey Monkey and analyzed using a thematic content analysis. The analysis was performed by the two investigators independently and then jointly. Data were grouped according to the participant's culture of origin (Akan, European American, and African-American) to allow a comparison of the experiences of each cultural group. The data were read for themes. Emerging themes were analyzed, interpreted, and compared across the three groups. Themes were related to the research questions guiding the study.

\section{Results: Emerging Themes}

Some of the important themes that emerged in this analysis included the following: (1) There was a strong and consistent belief in ancestor worship among the Akans of Ghana, and this was unique to the Akan respondents; (2) Among the European American responses in this study, it was not surprising to find that a variety of belief systems were 
apparent, and quite acceptable to believe different things pertaining to end-of-life issues; (3) Although all three cultural groups acknowledged some version of celebration at the end-of-life, there was variability as to how the celebratory aspect should be expressed. Results of the first theme - that of understanding Death as a Spiritual Event - is reported in all three cultural groups. Participants were asked what they think happens to a person when he or she dies. Participants' answers are spiritually focused.

\subsection{Akan Culture (Spirituality and Ancestorship)}

Participants believe that death is not the end of a person: Whereas nine believe that the deceased journeys to the ancestors, eight believe that the soul goes to heaven or hell when a person dies (religious). Three other participants believe that the soul goes to both heaven and to the ancestors. One participant stated:

"We Akans, representing a collective culture, believes that death is a journey to the ancestors, the dead hover around and protect the living, the dead have a hand in family members' progress, and that a funeral should be grand and successful".

Eighteen out of the 20 participants thus prefer burial to cremation. One participant made the following statement:

"It is a cultural thing, which I see to be better than cremation. This is because I believe in life after death. So that, if indeed there is resurrection, my body parts will be available to facilitate the process. In addition, I am a living entity deserving of honor. Any manner of disposing of my body other than burial will demean me as a person ... Even for many Akans who die abroad, the body is brought home for burial on ancestral land."

All 20 Akan participants believe that death could be classified as good or bad. According to participants, a bad death could be death at an early age, an accident, a violent death, or the result of a fearsome disease. Good death is when a person dies at an older age, having accomplished all business; is at peace with others before death; and is at peace with his or her own death. Such a death is celebrated. A participant summarized the belief as follows:

"If a person dies young, or commits suicide, it is bad death, but if a person accomplishes a lot, including having educated children, with good jobs, who are taking care of parents and family, and dies at old age, it is good death, and is celebrated with various rituals."

As stated earlier, death in this culture is believed to be a bridge between the world of the living and that of the spirits. Therefore, the deceased is believed to have contacts with the living. Thus, rituals emphasize the relationship between the living and the dead.

\subsection{European American Culture (Spirituality and Ancestorship)}

The European American culture is based on individualism. Eleven out of 20 participants responded that, after death, the soul transitions from the body into a spiritual dimension. One participant put it this way:

"I believe people are reincarnated. Each life is to perfect the soul and eventually the soul lives in heaven with God. I believe when someone dies they go to a better place. People use funerals to send their loved ones to God."

Another participant stated:

"First, death is a great mystery. Second, I am drawn to the concepts of Tao to learn how to embrace that mystery. The teachings of Tao offer me comfort and guidance for life on earth and the afterlife. I believe life and death are a single energy, so death is not something I fear. It is just a transformation that is the complement of life. I think I will cease to exist as "I" but will formlessly live on in oneness with the universe".

Twelve of the European American participants therefore believe that death is a transition into another life; they believe in afterlife or reincarnation. Others (eight) believe there is no afterlife, no heaven, and no hell; they think that the relationships built in this life are the only elements that survive a person. According to participants in this culture, there is nothing like ancestorship as it is understood in the Akan culture. Nor is there a good or bad death. To them, life must be preserved at all cost. Many are of the view that funeral practices are more important for those left behind. It is an important healing ritual that can move an individual toward closure and acceptance. Most (14) prefer cremation to burial.

\subsection{African-American Culture (Spirituality and Ancestorship)}

The African-American participants, like the Akans and European Americans, are of the view that death is inevitable. Fifteen of the 20 participants believe that a person's soul goes to heaven when he or she dies. For example, one African American participant stated: "When I die, my soul would be with Jesus in heaven. I will be in heaven where there will be no more pain, nor suffering. That belief keeps us going, in times of grieve."

This is in agreement with literature that observes African Americans, reliance on faith, hope, and prayer as means to cope (Barrett \& Heller, 2002). Four others were of the view that people's spirits may live on through other people's 
memories of them. As one participant put it, "It is up to us to make positive contributions in life, including having positive children, so our legacy lives on after death." Like the Akan participants, the African Americans believe in good and bad death. They view good death as a release from struggle and bad death as untimely. Also like the Akans, most African American participants (18) prefer burial to cremation. Many in these two cultures think that burial has its roots from Africa, where cremation is rare.

\subsection{Akan Culture (Life Celebration or Social Event)}

Most Akan participants (16) believe that a funeral is a celebration of the life of the deceased. It is an honor to the dead. The funeral must be celebrated and attended by relatives as well as others in the community. In Akan tradition, the funeral promotes family reunion and unity. One participant sums it:

"Akan funeral is celebrated by family and whole community ...Akans abroad, thanks to morgues and airplanes, come home to celebrate deceased members. We also believe in a decent burial and funeral for the dead. So our dead should be buried at home and not anywhere in a foreign land. Just as we celebrate the entrance of a person into life through birth, it is necessary that we celebrate a person's exit out of this world. In my culture we believe that the death of a person has to be celebrated in a manner that is deserved of the person when alive. We also believe in funeral as a communal event and I agree with these philosophies."

The celebrations and long ceremony provided by the Akans therefore serve as an opportunity for social readjustment. As Mbiti (1992) observes, the deceased continues to influence the lives of the living relatives with blessings and curses; therefore, funerals should be performed correctly. To the Akan participants, the funeral celebration is also a time to resolve conflicts, since almost everyone in the family is present. An Akan participant said: "It involves a sober reflection of one's own life. And in fact, during this occasion, even the hardhearted person calms down as lessons are drawn from the dead, hence the best time for solving family issues." However, a few respondents (four) think that the funeral practices and celebrations are sometimes too dramatic and involve unnecessary expenses. These participants acknowledge that funerals must be celebrated but people should spend according to their means. For example, one stated:

"But there's too much spending, especially in relation to economic spending, such as buying same (uniform) cloth to wear to remember the dead, assorted drinks, variety of foods served to sympathizers, etc. These things have turned funeral celebrations into some kind of "fashion show" instead of concentrating and celebrating the lives of the dead."

\subsection{European American Culture (Life Celebration or Social Event)}

European American participants are of the view that funerals are a celebration of life rather than an occasion for mourning the passing of a loved one. One participant remarked: "I attend funerals in order to see all of the connections that person made and how they affected their friends, how they celebrate the deceased's life and provide closure."

Others think that sharing in the life experiences of the deceased is important and helpful to the family. It gives people a chance to honor the one who passed and reconnect with each other. One participant summarized it as follows:

"During a time of loss, and grief there is comfort in the presence of friends and family. Perhaps the collective presence of all those that knew and loved the person somehow makes the pain of loss easier to bear."

Some indicated that European American funerals are less cumbersome.

\subsection{African-American Culture (Life Celebration or Social Event)}

Participants believe that a funeral is an event to be celebrated in honor of the dead person. As one respondent put it, "Culturally, funeral celebrations are to honor the dead persons and celebrate their lives. It is the time many families gather as a big group to reflect and take great decisions about the families' development."

Many in this culture believe that funerals are really for the benefit of those left behind. It is an aid for grieving. It allows the living to begin the process of closure after the loss. Others, however, believe that funerals are cumbersome.

\section{Discussion: Comparative Analysis}

From the findings of this study, all three cultures believe that the funeral is a way to have closure, to say goodbye, and to comfort the bereaved family; it is a time of support and a healing process. Grieving in a social context minimizes the pain of the bereaved and is noted to foster oneness, whereby bereaved families can be assisted in practical ways (Hoy, 2013; Neimeyer, 2012). Nearly half (41.2\%) of the participants in Hoy's (2013) study indicated that their presence with bereaved families emphasizes a quality relational community as an essential determinant of making meaning from their losses. Though many African American participants in our study indicated that their funerals are cumbersome, it is noted that Akan funerals are more cumbersome, and more time consuming, than the other two cultures. Unlike the 
funerals held by the Akans and African Americans, European American funerals are not the appropriate time for resolving family issues, and addressing such problems could tear families apart, as indicated by one of the participants.

\subsection{Biopsychosocial Aspects: Funeral as a Life Celebration or Social Event}

Both Akans and African Americans recognize the concepts of good and bad death. In Akan culture, good death is older death and bad death is younger or untimely death. In the African Americans culture, the concept of good death is the passing of someone at an advanced age or someone whose death is a release from struggle, and bad death is characterized by the unexpected passing of a younger person or a violent death. However, the European American culture lacks the concept of good death. In both Akan and African American cultures, care of the ill is mainly provided by the family. In the European American context, care is provided by family, hospitals, and nursing homes. The family's convenience plays a role in decisions about the source of care. In general, the life span of Akans is shorter than that of African Americans and European Americans; the differences may be due to the lack of an appropriate health care system. With European Americans, life is preserved at all costs by putting people on life support (Aries, 1974; Laderman, 2003). Thus, the advancement of technology and medicine favors life and longevity in the United States.

Both the Akans of Ghana and African Americans in the United States see death as a celebration of the deceased's life on earth. The funeral features music and dance. In both cultures, such celebrations foster a social bond: people come together; family and friends are obligated to be present. For European Americans, the funeral is more about mourning than about a grand celebration, and could be private. Although the Akans and African Americans show their grief and sorrow through loud crying and wailing, European Americans consider mourning to be solemn. Both Akan and African American cultures see the funeral event as a time to work out interpersonal conflicts in the family. For the European American culture, intrafamily conflict is often intensified at funerals. Family members in both the Akan and African American cultures are obliged to attend the funeral and to contribute to the funeral expenses; there is no such obligation in the European American culture. Unlike European American funerals, those in Akan and African American culture may be a time for socialization and networking. In the European American context, family and friends gather but the death event is not a time for socialization. Findings from our study show that the death rituals and celebrations observed among participants from these three groups are consistent with the practices reported in the literature (Barrett \& Heller, 2002; Hoy, 2013; Mcllwain, 2002; Markus \& Kitayama, 1991).

\subsection{Cultural Aspects: Death and Tradition}

There is diversity in the cultural aspects of the funeral celebrations examined. For example, in the Akan context death is celebrated with traditional clothes, music, and dance. The color of clothing is meaningful: Akans mainly wear red and black clothes in marking an untimely death, but the death of an older person (i.e., a good death) is marked by white clothes. In both African American and European American funerals, people are not obliged to wear a specific color. In the African American context, music is very important, but solos and choirs are common features of this music. In the European American context, anniversary dates may be acknowledged, but there are no commonly held rituals except the ones that individuals create to commemorate the death or to seek some aspect of closure. The Akans acknowledge the anniversaries of funerals with ceremonies (Kwakye-Nuako, 2011).

\subsection{Spiritual Aspects: Death and the Transition to Ancestorship}

Both Akans and African Americans mostly rely on faith, hope, prayers, and people to cope, in times of death, rather than on medical or mental health professionals. Both Akan and African American cultures prefer burial to cremation. According to their belief, the soul must go intact to the ancestral world or heaven. In the European American context, cremation or burial is accepted, and the choice between the two options is based on individual preference. The Akans also believe in ancestral presence and pray for the protection and guidance of the ancestors. Some African Americans in the study believe in ancestral presence. However, in the European American culture, there is no traditional ancestral worship. Findings from our study are consistent with the theories of independent and interdependent construals, as indicated in European American, and African American/Akan funeral practices respectfully.

\subsection{Implications for Practice}

This study offers some unique findings that can help practitioners working with clients from the three cultures studied. Although this paper offers some interesting comparisons, a pressing question remains: How can this information be used to enhance the provision of culturally sensitive services at the end of life? Professionals working with end-of-life concerns in the United States might already be sensitized to the uniqueness of individual choices made among Americans. However, the application of cultural sensitivity or cultural competence is not a static act. Rather, it is a continuous and fluid process that involves knowledge about cultural groups, attitudes, and beliefs. When one has knowledge about a cultural group, he or she may be inclined to reflect on the group's attitudes, values, and beliefs. And 
one may be inspired to take appropriate action to help individuals and families coping with a loss.

For example, this review documents many specific accounts of how death is traditionally celebrated in Akan culture. There are Ghanaians and other West Africans living throughout the United States. If there is a shared understanding of the importance of flying back home for an illness or a funeral, across many miles and at a great expense, these efforts should be facilitated, not judged. What we know about Akan funerals from the Akan participants in this study is that attending a funeral celebration and mourning with the bereaved is such an obligation that members of the bereaved family try to go home for funerals even if they live abroad. They do not count the cost of air fare to Ghana and other expenses. Therefore, the deceased's family members and friends in Ghana have no excuse for not attending hometown funerals (Twumasi, 2009; Kwakye-Nuako, 2011). It is also important to note that culture evolves and that the Akan funeral culture has gone through transformation. Modern technology and migration have contributed to this transformation. For instance, in Ghana, a corpse can be kept in a morgue for months, and air travel has made it possible for Akans living abroad to attend funerals at home, as indicated in this study. Death and bereavement are universal, but the rituals and celebrations that that go with them are diverse. For European Americans, it is important to provide funeral services, but with great respect for individual choices. Facilitating the unique ways in which individuals and families choose to honor their dead should be at the forefront of service provision, which may include helping the family to celebrate the deceased in privacy. For African Americans, however, respect for the family system and long-held traditions should be acknowledged and facilitated without judgment. It is noted for instance in this study that many African Americans rely on faith/prayer to cope. In this situation, the practitioner may involve their pastor in the healing process, if they so wish. The practitioner should provide space for an outward expression of grief without concluding that an abnormal grief reaction is taking place (e.g., complicated grief, (Currier, Holland, and Neimeyer, (2012). She or he should create an atmosphere where people feel comfortable to express their grief fully and without restraint. With European Americans, there is the need to respect individual wishes and privacy.

\section{Concluding Thoughts}

Provided in this study are perhaps some new ways to understand and work with people from cultural groups different than our own. It discusses how people make meaning of their loss and how they are supportive of each other. A central theme among people from West Africa is the importance of getting the people together and getting the body of the deceased back to Africa. Among European Americans, an understanding of individual choices and often quiet grieving are common themes. With African Americans, family and some long held traditions still persist. From the analysis in this paper, it can be surmised that many African American end-of-life traditions parallel those of the Akans of Ghana. It is interesting to note that, although African Americans have lived in the United States for over a century, their culture still maintain aspects reflective of African culture and traditions. European Americans indicated individual choices in funeral practices, many preferred cremation, and observe funeral as a solemn activity. Of course, cultural humility, sensitivity, and competence are crucial for anyone working in human services, and for practitioners supporting dying and bereaved families across cultures.

\section{References}

Aries, P. (1974). Western attitudes toward death: From middle ages to the present. Baltimore: John Hopkins University Press.

Arhin, K. (1994). The economic implications of transformations in Akan funeral rites. Africa: Journal of the International African Institute, 64(3), 307-322. http://dx.doi.org/10.2307/1160783

Barrett, R. K. (1995). Contemporary African-American funeral rites and traditions. In L. A. DeSpelder \& A. L.

Strickland (Eds.). The path ahead: Readings in death and dying, Mountain View, CA: Mayfield, 80-92.

Barrett, R. K., \& Heller, K. S. (2002). Death and dying in the Black experience. Journal of Palliative Medicine, 5, 793799. http://dx.doi.org/10.1089/109662102320880714

Borrell-Carrió, F., Suchman, A. L., \& Epstein, R. M. (2004). The biopsychosocial model 25 years later: Principles, practice, and scientific inquiry. Annals of Family Medicine, 2, 576-582. http://dx.doi.org/10.1370/afm.245

Callahan, D. (2009). Death, mourning, and medical progress. Perspectives in Biology and Medicine, 52(1), 103115.http://dx.doi.org/10.1353/pbm.0.0067

Clements, P. T., Vigil, G. J., Manno, M. S., Henry, G. C., Wilks, J., Sarthak, D., Kellywood, R., \& Foster, W.(2003). Cultural perspectives of death, grief, and bereavement. Journal of Psychosocial Nursing and Mental Health Services, 41(7), 18-26. http://dx.doi.org/10.3928/0279-3695-20030701-12

Coclanis, A. P., \& Coclanis, P. A. (2005). Jazz funeral: A living tradition. Southern Cultures, 11(2), 8692.http://dx.doi.org/10.1353/scu.2005.0015 
Currier, J. M., Holland, J. M., \& Neimeyer, R. A. (2012). Prolonged grief symptoms and growth in the first two years of bereavement: Evidence for a non-linear association. Traumatology, 18(4), 65-71. http://dx.doi.org/10.1177/1534765612438948

Engel, G. L. (1977). The need for a new medical model: A challenge for biomedicine. Science, 196, 129-136. http://dx.doi.org/10.1126/science.847460

Ephirim-Donkor, A. (1997). African spirituality: On becoming ancestors. Trenton, NJ: Africa World Press

Geest, V. D. S. (2006). Between death and funeral: Mortuaries and the exploitation of liminality in Kwahu, Ghana. Africa: The Journal of International African Institute, 76(4), 485-501. http://dx.doi.org/10.3366/afr.2006.0061

Geest, V. D. S. (2004). Dying peacefully: Considering good death and bad death in Kwahu- Tafo, Ghana. Social Science and Medicine, 58(5), 899-911. http://dx.doi.org/10.1016/j.socscimed.2003.10.041

Giblin, P., \& Hug, A. (2006). The psychology of funeral rituals. Liturgy, 21(1), 11-19. http://dx.doi.org/10.1080/04580630500285956

Hofstede, G. (1980). Culture's consequences: International differences in work-related values. Beverly Hills. CA:Sage.

Hoy, W. G. (2013). Do funerals matter? The purposes and practices of death rituals in global perspective. New York, NY: Routledge.

Jamieson, R. W. (1995). Material culture and social death: African American burial practices. Historical Archaeology, 29(4), 39-58.

Kwakye-Nuako, K. (2011). The enigma of life: Death rites among the Akans of Ghana and Christian eschatology. Journal of Religious Thought, 56/57(1), 1-20.

Laderman, G. (2003). Rest in peace: A cultural history of death and the funeral home in twentieth century America. New York: Oxford University Press.

Laurie, A., \& Neimeyer, R. A. (2008). African Americans in bereavement: Grief as a function of ethnicity. Omega, 57(2), 173-173. http://dx.doi.org/10.2190/OM.57.2.d

Lobar, S. L., Youngblut, J. M., \& Brooten, D. (2006). Cross-cultural beliefs, ceremonies, and rituals surrounding death of a loved one. Pediatric Nursing, 32(1), 44-50.

Markus, H. R., \& Kitayama, S. (1991). Culture and self: Implications for cognition, emotion and motivation. Psychological Review, 98, 224-253. http://dx.doi.org/10.1037/0033-295X.98.2.224

Mbiti J. S. (1992). African religions and philosophy (2nd ed.). London, United Kingdom: Heinemann.

Mcllwain, C. (2002). Death in Black and White: A study of family differences in the performance of death rituals. Qualitative Research Reports in Communication, 3(1), 1-6.

Moore, P. J. (2003). The Black church: A natural resource for bereavement support. Journal of Pastoral Counseling, 38, 47-57. Retrieved from http://www.jpcp.org/

Neimeyer, R. A. (Ed.). (2012). Techniques of grief therapy: Creative practices for counseling the bereaved. New York, NY: Taylor and Francis.

Oltjenbruns, K. A. (1998). Ethnicity and the grief response: Mexican American versus Anglo American college students. Death Studies, 22, 141-155. http://dx.doi.org/10.1080/074811898201641

Pappas, (S). After death: 8 burial alternatives that are going mainstream. http://www.livescience.com/15980-death 8-burial-alternatives.html

Patton, M. Q. (1990). Qualitative evaluation and research methods (2nd ed.). Newbury Park, CA: Sage Publications

Perry, H. L. (1993). Mourning and funeral customs of African Americans. In D. P. Irish, K. F. Lundquist, \& V. J. Nelsen (Eds.), Ethnic variations in dying, death, and grief: Diversity in universality, 51-65. Philadelphia, PA: Taylor \& Francis.

Smith, S. H. (2002). "Fret no more my child ... for I'm all over heaven all day": Religious beliefs in the bereavement of African American, middle-aged daughters coping with the death of an elderly mother. Death Studies, 26, 309-323. http://dx.doi.org/10.1080/074811802753594691

Taylor, R. J., Chatters, L. M., \& Jackson, J. S. (2007). Religious and spiritual involvement among older African

Americans, Caribbean Blacks, and non-Hispanic Whites: Findings from the National Survey of American Life. Journal of Gerontology: Social Sciences, 62B(4), S238-S250 
Twumasi, N. A. (2009, October 1). The Ghanaian way: Starve the living, splurge on the dead! Retrieved from Ghana Web website: http://www.ghanaweb.com/GhanaHomePage/features/artikel.php?ID=169543

Witte, M. D. (2001). Long live the dead! Changing funeral celebrations in Asante, Ghana. Amsterdam, the Netherlands: Aksant Academic Publishers

\section{(c) EY}

This work is licensed under a Creative Commons Attribution 3.0 License. 